\title{
Associations of Physiological State, Cognitive Function, Sensory Function, and Biochemical Index with Frailty Status Among Patients with Schizophrenia
}

\author{
Li-Hui Wu \\ National Taipei University of Nursing and Health Sciences \\ Ching-Yun Kao \\ The Saint Paul's Hospital \\ Shu-Fang Chang ( $\sim$ cygau0308@gmail.com ) \\ National Taipei University of Nursing and Health Sciences
}

\section{Research Article}

Keywords: schizophrenia, frailty, physiological state, cognitive function, sensory function

Posted Date: December 17th, 2021

DOI: https://doi.org/10.21203/rs.3.rs-1067053/v1

License: (0) (i) This work is licensed under a Creative Commons Attribution 4.0 International License. Read Full License 


\section{Abstract}

The literature on the prevalence and effect of the frailty status of patients with schizophrenia is limited. The interactions between frailty and psychiatric disorders warrant exploration. This study primarily aimed to explore the associations of physiological state, cognitive function, sensory function, and biochemical index with frailty status among patients with schizophrenia. A cross-sectional study design was adopted. Patients with schizophrenia were selected using purposive sampling. Frailty was revealed to be more prevalent with lower educational attainment, more hospitalization days, higher skeletal muscle percentage, higher basal metabolic rate, having fallen in the past year, use of anxiolytics or tranquilizers and sleeping pills, lower cognitive function, and use of assistive equipment. In addition, physiological state, cognitive function, and sensory function differed depending on the incidence of frailty among patients with schizophrenia. Cognitive function and the reduction of frailty incidence should be emphasized. Institutional nursing staff should regularly assess patients' frailty risk, pay attention to changes in patients' physiological state, monitor the cognitive function of patients, and recommend physical therapy and exercises to improve the strength, conditioning, and mobility of patients with schizophrenia for health maintenance and positive aging.

\section{Introduction}

Schizophrenia is a chronic mental illness characterized by severe thought disorders, and its lifetime prevalence is $1 \%$. Estimates indicate that this illness affects more than 20000000 people worldwide [1]. A study indicated that patients with schizophrenia have a high risk of premature death and that their life expectancy is 10-20 years shorter than the general population [2]. Although the findings of the aforementioned study are debated, several studies have indicated that schizophrenia may be a syndrome of accelerated aging [1, 2]. Therefore, age-related physiological changes and their clinical consequences (e.g., frailty and disability) may be common among schizophrenic patients. Frailty was initially defined as a decline in physiological reserves that is related to disability. Fried et al. [3] highlighted that frailty is a common clinical syndrome in older people that increases the risk for negative health outcomes, including falls, disability, hospitalization, and mortality. Most academic researchers believe that the phenotype of frailty is determined by the criteria of weight loss, self-reported exhaustion, weakness, slow walking speed, and low physical activity. Frailty is a multidimensional construct that is characterized by an increased vulnerability to stressors, and it can be described using a continuum of functional ability. Benraad et al. [4] conducted an observational study of a prospectively sampled cohort of older patients with mental illness; they reported that $53 \%$ of the 120 sampled patients were frail and had a high level of multimorbidity. Frailty generally tends to affect older adults. Its clinical symptoms include weight loss, decreased activity and appetite, muscle and bone loss, gait and balance disorders, and fatigue. Frailty may involve cognitive dysfunction, which is a syndrome that can trigger physiological disorders and susceptibility to complications [4]. The National Health Research Institutes analyzed the data of the Healthy Aging Longitudinal Study in Taiwan and determined that the comorbidities of frailty in older adults (aged 65 years or above) included hypertension, diabetes, and cardiovascular disease. In addition, the prevalence of comorbidities in older adults with frailty was higher than that in healthy and prefrail older adults [5]. Tsai et al. [6] examined the fall risk of 561 patients with schizophrenia. Their results revealed that $10.2 \%$ of the patients met the criteria for the frailty status, that the prevalence of frailty in patients aged 65 years or older was $28.1 \%$, and that low physical activity was associated with relatively high incidences of falling.

Psychotropic medication and chronic disease may play an essential role in the frailty and physical decline of patients with schizophrenia [7, 8]. Because of the long-term use of antipsychotic drugs, patients with schizophrenia tend to have abnormal blood glucose and lipid metabolism levels and cardiovascular disease [6]. Moreover, they are susceptible to unhealthy lifestyles (based on disease type), and their risk for other chronic diseases increases with time [6]. At present, frailty is a key area of research in geriatrics; however, its etiology is still being debated, and few studies have examined schizophrenic patients with frailty and the related risk factors. Therefore, a further exploration of such factors is warranted, and the results of such an exploration can serve as a reference for future health-care interventions.

\section{Aim and Hypothesis}

The main purpose of the present study was to explore the associations of physiological state, cognitive function, sensory function, and biochemical index with frailty status among patients with schizophrenia. This paper proposes the hypothesis that physiological state, cognitive function, sensory function, and biochemical index are associated with frailty among patients with schizophrenia.

\section{Methods}

Page 2/18 


\section{Participants}

In the present cross-sectional study, purposive sampling was used to collect relevant data on adults aged 55 years or older who were diagnosed with schizophrenia at a mental health-care home. The study period was from November 2019 to April 2020. The sample size was calculated using the $\mathrm{G}^{*}$ Power 3.1 software. An effect size (f2) of 0.15 , an á-value of 0.05 , and a power of 0.8 were substituted into the aforementioned program to obtain the required size (183).

\section{Inclusion Criteria}

The inclusion criteria were as follows: being aged 55 years or older, having a schizophrenia diagnosis, being in stable condition, being capable of communicating in Mandarin or Taiwanese, and being willing to participate in this study. The present study did not impose limits related to the status of frailty of the participants.

\section{Exclusion Criteria}

Individuals with severe sight and hearing impairments were excluded.

\section{Research Tools}

\section{Participant Characteristics}

Data were collected on sex, age, educational attainment, history of chronic disease, history of falls, hospitalization period, type of disease, and type of medication.

\section{Physiological State}

Physiological data included body mass index (BMI), which was automatically calculated using a BW-1116MH instrument (Nagata, Tainan, Taiwan). An InBody 370S instrument was used to conduct a bioelectrical impedance analysis (BIA) for assessing body composition. The results of a cross-sectional study of 232 young men, in which BIA was performed according to the index of muscle loss, indicated that the sensitivity and specificity of the InBody system were $73 \%$ and $95.9 \%$, respectively [9]. In the Mini Nutritional Assessment (MNA), the maximum score is 30 , a score of more than 17 but no more than 23.5 indicates risk of malnutrition, and a score of 24 or more indicates good nutritional status. At a geriatric outpatient clinic, the frailty status of 1003 older adults were screened using the MNA. The Cronbach's alpha for the internal consistency of the MNA was .730 . The MNA's retest reliability correlation coefficient was .776, its test sensitivity was $45.7 \%-71.2 \%$, and its test specificity was $78.3 \%-92.8 \%[10]$.

\section{Cognitive Function}

Folstein et al. [11] developed the Mini-Mental State Examination (MMSE) scale, which includes items such as orientation, information registration, attention and calculation skills, short-term memory, and language comprehension. This scale was translated into Chinese by Guo et al. [12] and is currently the most commonly used screening tool in clinical epidemiological research on cognitive dysfunction (Chiu \& Tang, 2006). The aforementioned scale comprises 11 items. The MMSE scale is scored from 0 to 30, with a higher score indicating better cognitive function, and a score of 23 or less indicates potential cognitive deficits such as dementia or delusion. A study reported that for the diagnosis of intellectual disability, the MMSE scale has a sensitivity of $85 \%$ and specificity of $82 \%$ [13]. This scale is affected by educational attainment, and the scores of patients with dementia may exceed 24, whereas those of other patients may be less than 24 because of low educational attainment even when they are not cognitively impaired [14]. In one study, the MMSE scale had a retest reliability of .56-.98, a scoring validity of .82, and a Cronbach's alpha value (for internal consistency) of .96 [11]. A Cronbach's alpha value of .86 was reported for the MMSE scale in a study on older inpatients [15].

\section{Sensory Function}

The present study used the Snellen eye chart to assess participants' visual acuity and a diapason to test their hearing. Furthermore, the presence or absence of teeth and use of assistive equipment were noted.

\section{Frailty}


The Study of Osteoporotic Fractures (SOF) index developed by Ensrud et al. [16] was adopted as the criterion for assessing frailty. This measurement method assesses the following items: (1) whether a patient has experienced unintentional weight loss in the past year (i.e., a weight loss of more than $3 \mathrm{~kg}$ or $5 \%$ of one's body weight), (2) the ability of a patient to stand up from a chair five times without using their arms, and (3) a patient's self-perceived vitality (assessed by asking a patient if they feel full of vitality). Frailty is recognized when two or more criteria are met, prefrailty is recognized when one criterion is met, and absence of frailty is recognized when no criterion is met. Luciani et al. [17] assessed the sensitivity, specificity, and accuracy of the SOF index for older patients with cancer. They reported that relative to a comprehensive geriatric assessment, this index's sensitivity, specificity, and accuracy were $89.0 \%, 81.1 \%$, and $86.5 \%$, respectively, which indicates that it can identify $89.0 \%$ of patients with frailty and $81.1 \%$ of patients without frailty. A comparative analysis of 471 community older adults aged over 65 years in Taiwan was conducted using the SOF index and Fried's frailty phenotype. The results indicated that Fried's frailty phenotype was moderately different from the SOF index $(p<.001)$. The effectiveness of predictions, which was assessed on the basis of the area under the curve, indicated that the SOF index was reliable for predicting fall risk $(p<.001)$ [18].

\section{Sample size}

According to the logistic regression analysis formula and the calculations made using G*Power 3.1, a minimum sample size of 182 participants was required to achieve a power of 0.8 and an á-value of 0.05 . The effect size is a numerical value that quantifies the intensity of a phenomenon.

\section{Data Collection and Statistical Analysis}

Quantitative data were analyzed using SPSS Statistics 22 and tested according to the research objective and characteristics of the variables. Continuous variables were presented as means \pm standard deviations (SDs), and categorical variables were presented as numbers and percentages. A chi-square test was used to identify differences between categorical variables. Analyses of variance and the Scheffe test for post hoc analysis were performed to examine differences among continuous variables and frailty groups. The multivariable logistic regression method was used to identify differences among risk factors and various stages of frailty, with the reference category being patients without frailty. All the statistical analyses were performed using SPSS Version 15 software (IBM, Armonk, NY, USA). A p value of 0.05 was used as the cutoff value for statistical significance.

\section{Ethical Approval}

The study was approved by the research ethics review committee of Yuli Hospital, Ministry of Health and Welfare, Republic of China (IRB code: YLH-IRB-10809). All methods were performed in accordance with the STROBE guideline for the observational studies. In addition, to protect the privacy and rights of enrolled patients, they were informed of the purpose, methods, and period of this study, after which they were asked to sign a written consent form. The information obtained was used for academic purposes only and was strictly confidential.

\section{Results}

\section{Characteristics of Patients with Schizophrenia}

The participants comprised 183 patients with schizophrenia. They were divided into the "no frailty" (44 participants; 24\%), "prefrailty" (119 participants; 65\%), and "frailty" (20 participants; 11\%) groups. Of the participants, 110 were men (60.1\%) and 73 were women $(39.9 \%)$, and their average age was 65.48 years $(S D=6.00$ years). Participants with primary school education (70 participants) comprised $38.8 \%$ of all the participants. For the majority of the participants (51.9\%), the number of hospitalization days was more than 15 years.

With regard to the history of chronic disease, most of the participants had diabetes (88 participants; $48.1 \%$ ). A total of $3.3 \%$ of the participants fell once within a year (six participants). With regard to medicine type and usage, the majority of the participants took standard medicine, that is, second-generation antipsychotics (160 participants; $87.4 \%$ ). The participants' BMI ranged from 17.00 to $43.70 \mathrm{~kg} / \mathrm{m}^{2}$, with their average BMI being $25.18 \mathrm{~kg} / \mathrm{m}^{2}\left(\mathrm{SD}=4.03 \mathrm{~kg} / \mathrm{m}^{2}\right)$. A total of $66(36.1 \%)$ participants were in the healthy weight range. 
The participants' average weight of body fat was $22.1 \mathrm{~kg}(\mathrm{SD}=8.3 \mathrm{~kg})$, their average skeletal muscle mass was $23.84 \mathrm{~kg}(\mathrm{SD}=4.5$ $\mathrm{kg}$ ), their average basal metabolic rate was $1315.2(\mathrm{SD}=160.14)$, and their average waist-to-hip ratio was $0.90(\mathrm{SD}=0.07)$. The MNA indicated that 171 participants had normal nutritional status $(93.4 \%)$ and that 12 participants were at risk of malnutrition (6.6\%). The participants' cognitive function scores ranged from 11 to 30 , with the majority (100 participants; $54.6 \%$ ) scoring between 24 and 30 , which indicated normal cognitive function. For visual acuity, the participants' scores for the left eye ranged from 0.2 to 1.5 , and their scores for the right eye ranged from 0.1 to 2.0 . A total of $34(18.6 \%)$ participants had cataracts. The majority of the participants had normal hearing (172 participants; 94\%). With regard to dental status, 180 participants had missing teeth (98.4\%), and 15 participants had false teeth (8.2\%). With respect to use of assistive equipment, seven participants used wheelchairs (3.8\%), and eight participants used walkers (4.4\%).

The participants' biochemical index results (Table 1) are described in the following text. For liver function, the average SGPT value was $23 \mathrm{U} / \mathrm{L}(\mathrm{SD}=17.6 \mathrm{U} / \mathrm{L})$; for kidney function, the average level of creatinine was $1 \mathrm{mg} / \mathrm{dL}(\mathrm{SD}=0.34 \mathrm{mg} / \mathrm{dL})$; for blood glucose, the average level of glucose AC was $100.16 \mathrm{mg} / \mathrm{dL}(\mathrm{SD}=21.58 \mathrm{mg} / \mathrm{dL}$ ); the average total cholesterol level was $135.55 \mathrm{mg} / \mathrm{dL}$ (SD $=27.51 \mathrm{mg} / \mathrm{dL}$ ); the average level of high-density lipoprotein was $45.55 \mathrm{mg} / \mathrm{dL}(\mathrm{SD}=12.30 \mathrm{mg} / \mathrm{dL}$ ); the average level of low-density lipoprotein was $71.33 \mathrm{mg} / \mathrm{dL}(\mathrm{SD}=24.22 \mathrm{mg} / \mathrm{dL})$; and the average level of triglyceride was $106.23 \mathrm{mg} / \mathrm{dL}(\mathrm{SD}=47.07 \mathrm{mg} / \mathrm{dL})$.

\section{Differences in Attributes and Physiological State Among Patients with Varying Levels of Frailty}

Table 2 indicates that patients with varying levels of frailty exhibited significant differences with respect to educational attainment, hospitalization duration, history of falls in the past year, use of anxiolytics or tranquilizers and sleeping pills, level of cognition, and use of assistive equipment $\left(\chi^{2}=114.882 ; p<.001\right)$. No significant difference was observed for the other variables with the participants' level of frailty.

Table 3 indicates significance differences in skeletal muscle percentage $(F=5.256, p<.01)$ among patients with varying levels of frailty, which suggested that the physiological state of the patients with schizophrenia differed significantly with frailty. A further comparison revealed that level of frailty decreased when skeletal muscle percentage increased. Significance differences in basal metabolic rate $(F=4.971, p<.01)$ were observed among patients with varying levels of frailty, which indicated that the patients' basal metabolic rate differed significantly with frailty. A further comparison revealed that frailty increased with basal metabolic rate. Significance differences in cognitive function $(F=8.726, p<.001)$ were observed among patients with varying levels of frailty, which indicated that the patients' MMSE scores differed significantly with frailty. A further comparison revealed that a higher score for cognitive function (i.e., lower cognitive dysfunction) was differed with a lower level of frailty and that frailty was more severe among patients with severe cognitive dysfunction than among those with normal cognitive function.

\section{Predicting Frailty in Patients with Schizophrenia Through the Physiological State and Health State}

Because logistic regression does not consider multicollinearity, multinomial logistic regression was used to examine the predictive ability of basic attributes, physiological state, cognitive function, and sensory function for frailty. The results for each factor were calculated with respect to the reference category for non-frailty. The results revealed that cognitive function $(\beta=-0.108, p<.05)$, use of an assistive wheelchair $(\beta=3.502, p<.01)$, and use of a walker $(\beta=4.247, p<.001)$ could effectively predict frailty (Table 4).

\section{Discussion}

The participants of the present study were patients with schizophrenia who were aged 55 years or older and living at a mental health-care home. With regard to educational attainment, those with primary school education accounted for the highest percentage of the participants. This finding is similar to that of a survey of long-term chronic psychiatric inpatients, in which illiterate participants and participants with primary school education formed the majority of the participants [19]. In the present study, the prevalence of frailty was $11 \%$. This finding is similar to those reported by a survey conducted by Wu et al. [20] on frailty among older male adults in Southern Taiwan (prevalence of frailty was 11.6\%) and a survey conducted by Tseng et al. [21] on frailty among older residents in long-term care institutions (11.1\%). Chou et al. [22] studied the frailty of inpatients aged over 65 years in a medical center in Southern Taiwan and the related influencing factors. They recruited 124 participants and reported that the prevalence of frailty among the participants was $88.7 \%$, with the level of frailty increasing with age. These results correspond to those reported in the present study. The screening scales for frailty that are commonly used internationally include the SOF index, the frailty 
phenotype of the Cardiovascular Health Study, and the Clinical Frailty Scale. Because of the varying attributes of research participants, no consistent standard has been established regarding the use of these scales. However, studies on frailty in patients with mental disorders indicate that frailty indicators can predict the mortality of patients during hospitalization $[3,23]$.

In the present study, significant differences were observed among patients with varying levels of frailty in terms of educational attainment, hospitalization duration, history of falls in the past year, use of anxiolytics or tranquilizers and sleeping pills, cognitive function, and use of assistive equipment. This finding corresponds to that of a study on 582 patients with chronic schizophrenia at a mental institution, which reported that frailty can be regarded as a mechanism for the risk of fall in these patients [6]. Studies have examined psychiatric patients in nursing homes, cases of frailty in older adults, and criteria for inappropriate prescription. The results of these studies suggest that frailty is associated with the use of anxiolytics or tranquilizers, sleeping pills, antipsychotics, and anticholinergics $[24,25]$. These findings are consistent with those of the present study. For history of chronic disease among the participants in the present study, diabetes was most common disease, followed by hypertension. This finding is similar to that of a study on the physiological traits of patients with schizophrenia, which found that the average fasting blood glucose of patients with schizophrenia was higher than that of the healthy control group and that the proportion of patients with hyperglycaemia was higher among the patients with schizophrenia than among the control group [26]. Significant differences were observed among patients with varying levels of frailty in terms of cognitive status scores and cognitive function grouping, which indicates that patients with varying levels of frailty exhibited significantly different levels of cognitive function (i.e., MMSE scores). Studies have integrated analyses of frailty and cognitive impairment, and their results have revealed that frailty is associated with risk for cognitive dysfunction $[27,28]$. Furthermore, in a study of the frailty and health status of self-financed older adults in long-term care institutions, substantial differences in cognitive function were observed among participants with varying levels of frailty [29].

The results of this study reveal that cognitive function, use of an assistive wheelchair, and use of a walker can effectively predict frailty. These findings correspond to those of a study by Ong et al. [30], who investigated 110 long-term inpatients with schizophrenia and schizoaffective disorders in Singapore and reported that those with earlier onsets and more hospitalization days scored lower on the MMSE scale. With regard to eye health, cataracts were common among the participants in the present study. The use of medicine by psychiatric patients may induce various ocular disorders, including cataracts, glaucoma, and retinopathy. Retinopathy is verified to be associated with the use of high-dose typical antipsychotic, and its occurrence is proportional to the total amount of long-term medication used [31]. The present study revealed that the use of assistive devices is a significant predictor of frailty. This finding is similar to that reported by Lu et al. (2010), who examined frailty among older chronic inpatients and discovered that mobility barriers are a predictor of frailty. Dedeyne et al. [32] reviewed the literature on the effects of diverse interventions on the cognitive state of older individuals with frailty. Their results revealed that relative to single interventions, multifaceted interventions produced better outcomes for improving physical function and muscle strength. Tsugawa et al. [33] studied the cognitive status of nursing home residents in relation to exercise interventions. Their results indicated that exercise interventions can effectively improve the cognitive function of care home residents who require long-term nursing care. Few studies have examined the associations of physiological state, cognitive function, sensory function, and biochemical indicators with the frailty status of patients with schizophrenia. Research has identified the partial association of frailty with the physiological state, cognitive function, and sensory function of patients with schizophrenia. Therefore, when caring for patients with schizophrenia, medical staff should regularly assess their frailty risk, pay attention to changes in their physiological state, monitor their cognitive functions, and use appropriate assistive devices to help these patients improve their physical functions, which would enable them to maintain their health and engage in active aging.

\section{Limitations}

This study adopted a cross-sectional and quantitative framework; therefore, its results only reflect the statuses of and differences among the considered variables during the period of enrollment. The results of this study pertain only to the differences in the demographic attributes, physiological states, cognitive function, sensory function, and biochemical indices for frailty among patients with schizophrenia at a mental health-care home in Hualien. Because no samples were obtained from mental health-care homes in other regions, the generalizability of the results is limited.

\section{Conclusion}


The findings of the present study indicate the associations of physiological state, cognitive function, and sensory function with the incidence of frailty among patients with schizophrenia. Attempts should be made to improve cognitive function and action ability to decrease the incidence of frailty. Because a causal relationship between cognitive function and action ability has not been found, these factors may be appropriate predictors of frailty and may be included in a future measure of frailty. Notably, the investigated patients were already affected by schizophrenia, and their attributes were more complex than those of patients with other chronic illnesses.

\section{Nursing Implications}

When providing care to patients with schizophrenia, nursing staff should regularly assess frailty risk, pay attention to changes in physiological states, monitor cognitive function, and reduce the use of assistive devices, all of which would help improve the body functions of these patients and promote their health maintenance and positive aging.

\section{Clinical Resources}

- Department of Health, R.O.C. (Taiwan). Healthy people 2020: http://www.doh.gov.tw/CHT2006/index populace.aspxr

- World Health Organization: Frailty health http://www.who.int/ageing/about/whoactivities/en/index1.htm

\section{Declarations}

\section{Ethics approval and consent to participate}

The study was approved by the research ethics review committee of Yuli Hospital, Ministry of Health and Welfare, ROC (IRB code: YLH-IRB-10809). All methods were performed in accordance with the STROBE guideline for the observational studies. In addition, to protect the privacy and rights of patients, they were clearly informed of the purpose, methods, and period of the study, and they signed a consent form. The information obtained was for academic use only and was strictly confidential.

\section{Author information}

\section{Affiliations}

1. Department of Nursing, College of Nursing, National Taipei University of Nursing and Health Sciences, Pei-Tou, Taipei, 11280, Taiwan

Li-Hui Wu, Shu-Fang Chang

\section{Saint Paul's Hospital, Taoyuan, 330049, Taiwan}

Ching-Yun Kao

\section{Author Contributions}

Study design: Shu-Fang Chang, Li-Hui Wu, and Ching-Yun Kao; data collection and analysis: Li-Hui Wu; and manuscript preparation: Shu-Fang Chang, Li-Hui Wu

\section{Funding}

Authors would like to acknowledge for receiving the Saint Paul's Hospital Grant 110D003-3 in Taiwan.

\section{Data Availability Statement}

Data can be accessed from the corresponding authors on reasonable request.

\section{Consent for publication}

Not applicable. 
Author would like to thank the Ministry of Science and Technology of the R.O.C., for financially supporting this research under Contract No. MOST 108-2622-B-227-001- CC2.

\section{Conflicts of Interest}

The authors declare that they have no competing interests.

\section{References}

1. World Health Organization. Schizophrenia. Available online: https://www.who.int/en/news-room/factsheets/detail/schizophrenia (accessed on 4 October 2019).

2. Hjorthoj, C.; Sturup, A.E.; McGrath, J.J.; Nordentoft, M. Years of potential life lost and life expectancy in schizophrenia: A systematic review and meta-analysis. Lancet Psychiatry 2017, 4, 295-301.

3. Fried, L.P.; Tangen, C.; Walston, J.; Newman, A.B.; Hirsch, C.; Gottdiener, J.; ...McBurnie, M.A. Frailty in older adults: evidence for a phenotype. The Journals of Gerontology Series A: Biological Sciences and Medical Sciences <bi>2001</bi>, 56, M146-M157.

4. Benraad, C.E.M.; Disselhorst, L.; Laurenssen, N.C.W.; Hilderink, P.H.; Melis, R.J.F.; Spijker, J.; Olde Rikkert, M.G.M. Frailty, multimorbidity and functional status as predictors for health outcomes of acute psychiatric hospitalisation in older adults. Aging Ment. Health 2020, 24, 119-128.

5. Xie, C.C.; Xiao, Y.Y.; Lin, M.Q.; Chen, B.Q. Lao Ren Shuai Ruo Zheng. Family Med. Prim. Med. Care 2010, 25, 410-417.

6. National Health Research Institutes. NHRI Communications. Available online:

http://enews2.nhri.org.tw/enews_list_new2_more.php?volume_indx=599\&showx=showarticle\&article_indx=10493 (accessed on 2015).

7. Tsai, M.T.; Chang, T.H.; Wu, B.J. Prognostic impact of nutritional risk assessment in patients with chronic schizophrenia. Schizophr. Res. 2018, 192, 137-141.

8. Strandberg, T.E.; Stenholm, S.; Strandberg, A.Y.; Salomaa, V.V.; Pitkala, K.H.; Tilvis, R.S. The "obesity paradox," frailty, disability, and mortality in older men: A prospective, longitudinal cohort study. Am. J. Epidemiol. 2013, 178, 1452-1460.

9. Teasdale, S.B.; Ward, P.B.; Rosenbaum, S.; Samaras, K.; Stubbs, B. Solving a weighty problem: Systematic review and metaanalysis of nutrition interventions in severe mental illness. Br. J. Psychiatry 2017, 210, 110-118.

10. Alkahtani, S.A. A cross-sectional study on sarcopenia using different methods: Reference values for healthy Saudi young men. BMC Musculoskelet. Disord. 2017, 18, 119.

11. Soysal, P.; Veronese, N.; Arik, F.; Kalan, U.; Smith, L.; Isik, A.T. Mini nutritional assessment scale-short form can be useful for frailty screening in older adults. Clin. Interv. Aging 2019, 14, 693-699.

12. Folstein, M.F.; Folstein, S.E.; McHugh, P.R. "Mini-mental state”: A practical method for grading the cognitive state of patients for the clinician. J. Psychiatr. Res. 1975, 12, 189-198.

13. Guo, N.W.; Liu, X.Z.; Wang, P.F.; Liao, G.G.; Zhen, R.X.; Lin, G.P.; Chen, Z.Y.; Xu, D.C. Chinese version and norms of the mini-mental state examination. J. Rehabil. Med. Assoc. 1988, 16, 52-59.

14. Karuza, J.; Katz, P.R.; Henderson, R. Cognitive screening. In Assessing the Health Status of Older Adults, 1997, pp. 143-179.

15. Anthony, J.C.; LeResche, L.; Niaz, U.; Von Korff, M.R.; Folstein, M.F. Limits of the 'Mini-Mental State'as a screening test for dementia and delirium among hospital patients. Psychol. Med. 1982, 12, 397-408.

16. Dai, Y.T.; Yip, P.K.; Huang, G.S.; Lou, M.F. Cognitive function of elderly patients. Formos. J. Med. 1999, 3, 279-286.

17. Ensrud, K.E.; Ewing, S.K.; Taylor, B.C.; Fink, H.A.; Cawthon, P.M.; Stone, K.L.; Hillier, T.A.; Cauley, J.A.; Hochberg, M.C.; Rodondi, N. Comparison of 2 frailty indexes for prediction of falls, disability, fractures, and death in older women. Arch. Intern. Med. 2008, $168,382-389$.

18. Luciani, A.; Dottorini, L.; Battisti, N.; Bertuzzi, C.; Caldiera, S.; Floriani, I.; Zonato, S.; Ferrari, D.; Foa, P. Screening elderly cancer patients for disabilities: Evaluation of study of osteoporotic fractures (SOF) index and comprehensive geriatric assessment (CGA). Ann. Oncol. 2012, 24, 469-474. 
19. Hu, B.; Hsiao-Wei, Y.; Chiu, T.; Li-Ling, L.; Chen, Y. The validity of the Study of Osteoporotic Fractures (SOF) index for assessing community-based older adults in Taiwan. Innov. Aging 2018, 2, 1015.

20. Shafie, S.; Lee, S.P.; Ong, S.B.C.; Wang, P.; Seow, E.; Ong, H.L.; Chong, S.A.; Subramaniam, M. Prevalence and correlates of diabetes mellitus and dyslipidaemia in a long-stay inpatient schizophrenia population in Singapore. Singapore Med. J. 2018, 59, 465-471.

21. Wu, P.Y.; Hou, M.T.; Chang, C.L.; Chang, C.S.; Chen, C.Y.; Yang, Y.C.; Chang, C.M.; Wu, C.H. Prevalence and associated risk factors of frailty in elderly male rural dwellers in Southern Taiwan. Taiwan Geriatr. Gerontol. 2011, 6, 161-175.

22. Tseng, M.Y.; Tu, S.Y.; Lin, C.C.; Hsu, S.M. A study on the frailty status among elderly in a long-term care facility. J. M. U. 2015, 34, $1-15$.

23. Chou, M.H.; Chen, F.J.; Chiu, C.F.; Lin, Y.T. Factors influencing frailty in elderly hospitalized patients. VGH Nurs. 2019, 36, $27-38$.

24. Stolz, E.; Rásky, É.; Jagsch, C. Frailty index predicts geriatric psychiatry inpatient mortality: A case-control study. Psychogeriatrics 2020, 20, 469-472.

25. Maclagan, L.C.; Maxwell, C.J.; Gandhi, S.; Guan, J.; Bell, C.M.; Hogan, D.B.; Daneman, N.; Gill, S.S.; Morris, A.M.; Jeffs, L.; et al. Frailty and potentially inappropriate medication use at nursing home transition. J. Am. Geriatr. Soc. 2017, 65, 2205-2212.

26. Muhlack, D.C.; Hoppe, L.K.; Saum, K.U.; Haefeli, W.E.; Brenner, H.; Schöttker, B. Investigation of a possible association of potentially inappropriate medication for older adults and frailty in a prospective cohort study from Germany. Age Ageing 2019, $49,20-25$.

27. Chen, P.H.; Tsai, S.Y.; Kuo, C.J.; Chung, K.H.; Huang, S.H.; Chen, C.C. Physiological characteristics of patients with schizophrenia prematurely dying from circulatory diseases. Asia. Pac. Psychiatry 2016, 8, 199-205.

28. Borges, M.K.; Canevelli, M.; Cesari, M.; Aprahamian, I. Frailty as a predictor of cognitive disorders: A systematic review and metaanalysis. Front Med (Lausanne). 2019, 6, 26.

29. Furtado, G.E.; Letieri, R.; Hogervorst, E.; Teixeira, A.B.; Ferreira, J.P. Physical frailty and cognitive performance in older populations, part I: Systematic review with meta-analysis. Cien. Saude Colet. 2019, 24, 203-218.

30. Peng, H.J. Exploration the Association between Frailty Status and Sleep Quality among Older Adults Living in Self-Paid Care Home, National Taipei University of Nursing and Health Sciences: Taipei City, Taiwan, 2016.

31. Ong, H.L.; Subramaniam, M.; Abdin, E.; Wang, P.; Vaingankar, J.A.; Lee, S.P.; Shafie, S.; Seow, E.; Chong, S.A. Performance of MiniMental State Examination (MMSE) in long-stay patients with schizophrenia or schizoaffective disorders in a psychiatric institute. Psychiatry Res. 2016, 241, 256-262.

32. Richa, S.; Yazbek, J.C. Ocular adverse effects of common psychotropic agents: A review. CNS Drugs 2010, 24, 501-526.

33. Dedeyne, L.; Deschodt, M.; Verschueren, S.; Tournoy, J.; Gielen, E. Effects of multi-domain interventions in (pre)frail elderly on frailty, functional, and cognitive status: A systematic review. Clin. Interv. Aging 2017, 12, 873-896.

34. Tsugawa, A.; Shimizu, S.; Hirose, D.; Sato, T.; Hatanaka, H.; Takenoshita, N.; Kaneko, Y.; Ogawa, Y.; Sakurai, H.; Hanyu, H. Effects of 12-month exercise intervention on physical and cognitive functions of nursing home residents requiring long-term care: $\mathrm{A}$ non-randomised pilot study. Psychogeriatrics. 2020, 20, 419-426.

35. Cruz, D.T.D.; Vieira, M.T.; Bastos, R.R.; Leite, I.C.G. Factors associated with frailty in a community-dwelling population of older adults. Rev. Saude Publica. 2017, 51, 106.

36. Dieset, l.; Andreassen, O.A.; Haukvik, U.K. Somatic comorbidity in schizophrenia: Some possible biological mechanisms across the life span. Schizophr. Bull. 2016, 42, 1316-1319.

37. Jayanama, K.; Theou, O.; Blodgett, J.M.; Cahill, L.; Rockwood, K. Frailty, nutrition-related parameters, and mortality across the adult age spectrum. BMC Med. 2018, 16, 188.

38. Lorenzo-López, L.; Maseda, A.; de Labra, C.; Regueiro-Folgueira, L.; Rodríguez-Villamil, J.L.; Millán-Calenti, J.C. Nutritional determinants of frailty in older adults: A systematic review. BMC Geriatr. 2017, 17, 108.

39. Maltais, J.R.; Gagnon, G.; Garant, M.P.; Trudel, J.F. Correlation between age and MMSE in schizophrenia. Int. Psychogeriatr. 2015, $27,1769-1775$.

40. Murukesu, R.R.; Singh, D.K.A.; Subramaniam, P.; Tan, X.V.; Mohamd Izhar, I.A.; Ponvel, P.; Mohd Rasdi, H.F. Prevalence of frailty and its association with cognitive status and functional fitness among ambulating older adults residing in institutions within West Coast of Peninsular Malaysia. Int. J. Environ. Res. Public Health 2019, 16, 4716.

Page 9/18 
41. Robertson, D.A.; Savva, G.M.; Kenny, R.A. Frailty and cognitive impairment-a review of the evidence and causal mechanisms. Ageing Res. Rev. 2013, 12, 840-851.

42. Tavares, D.M.D.S.; Colamego, C.G.; Pegorari, M.S.; Ferreira, P.C.D.S.; Dias, F.A.; Bolina, A.F. Cardiovascular risk factors associated with frailty syndrome among hospitalized elderly people: A cross-sectional study. Sao Paulo Med. J. 2016, 134, 393-399.

43. Tombaugh, T.N.; Mclntyre, N.J. The mini-mental state examination: A comprehensive review. J. Am. Geriatr. Soc. 1992, 40, 922935.

44. Viertiö, S.; Perälä, J.; Saarni, S.; Koskinen, S.; Suvisaari, J. Hearing loss in persons with psychotic disorder-findings from a population-based survey. Schizophr. Res. 2014, 159, 309-311.

\section{Tables}

Table 1. Attributes, physiological state, cognitive function, sensory function, and biochemical indices of patients with schizophrenia $(\mathrm{N}=183)$. 


\begin{tabular}{|c|c|c|c|c|c|}
\hline Category & Number & Percentage (\%) & Range & Average & SD \\
\hline \multicolumn{6}{|l|}{ Stage of frailty } \\
\hline Normal & 44 & 24 & & & \\
\hline Prefrailty & 119 & 65 & & & \\
\hline Frailty & 20 & 11 & & & \\
\hline \multicolumn{6}{|l|}{ Sex } \\
\hline Male & 110 & 60.1 & & & \\
\hline Female & 73 & 39.9 & & & \\
\hline Age & & & $55-87$ & 65.48 & 6.00 \\
\hline $55-59$ years & 51 & 27.9 & & & \\
\hline $60-64$ years & 68 & 37.2 & & & \\
\hline $65-69$ years & 34 & 18.6 & & & \\
\hline $70-74$ years & 20 & 10.9 & & & \\
\hline 75 years or above & 10 & 5.5 & & & \\
\hline \multicolumn{6}{|l|}{ Educational attainment } \\
\hline No education & 3 & 1.6 & & & \\
\hline Primary school & 70 & 38.3 & & & \\
\hline Junior high school & 63 & 34.4 & & & \\
\hline Senior high school & 33 & 18 & & & \\
\hline Junior college & 14 & 5.5 & & & \\
\hline University & 4 & 2.2 & & & \\
\hline \multicolumn{6}{|l|}{ Hospitalization duration } \\
\hline $1-5$ year(s) & 4 & 2.2 & & & \\
\hline $6-10$ years & 17 & 9.3 & & & \\
\hline $11-15$ years & 67 & 36.6 & & & \\
\hline$>15$ years & 95 & 51.9 & & & \\
\hline \multicolumn{6}{|l|}{ Physiological condition } \\
\hline \multicolumn{6}{|l|}{ History of chronic disease } \\
\hline Yes & 178 & 97.3 & & & \\
\hline No & 5 & 2.7 & & & \\
\hline Hypertension & 63 & 34.4 & & & \\
\hline Diabetes & 88 & 48.1 & & & \\
\hline Hyperlipidaemia & 32 & 17.5 & & & \\
\hline Cardiovascular disease & 56 & 30.6 & & & \\
\hline Kidney disease & 60 & 32.8 & & & \\
\hline Hepatitis or cirrhosis & 40 & 21.9 & & & \\
\hline Cancer & $\begin{array}{l}12 \\
\text { Page } 1\end{array}$ & $\begin{array}{c}6.6 \\
118\end{array}$ & & & \\
\hline
\end{tabular}


History of falls

\begin{tabular}{|c|c|c|c|c|c|}
\hline Yes & 6 & 3.3 & & & \\
\hline No & 177 & 96.7 & & & \\
\hline \multicolumn{6}{|l|}{ Type of medicine } \\
\hline Traditional antipsychotics & 56 & 30.6 & & & \\
\hline Second-generation antipsychotics & 160 & 87.4 & & & \\
\hline Antidepressant & 12 & 6.6 & & & \\
\hline Mood stabilizers & 44 & 24 & & & \\
\hline Anxiolytics/tranquilizers and sleeping pills & 100 & 54.6 & & & \\
\hline \multicolumn{6}{|l|}{$\mathrm{BMI} \mathrm{kg/ \textrm {m } ^ { 2 }}$} \\
\hline Underweight: $<18.5$ & 7 & 3.8 & & & \\
\hline Healthy weight range: $18.5-24$ & 66 & 36.1 & & & \\
\hline Overweight: $24-27$ & 52 & 28.4 & & & \\
\hline Obesity: >27 & 58 & 31.7 & & & \\
\hline \multicolumn{6}{|l|}{ Body composition analysis } \\
\hline Weight of body fat & 163 & & $4.60-57.4$ & 22.1 & 8.3 \\
\hline Skeletal muscle mass & 163 & & $15.2-36.3$ & 23.8 & 4.5 \\
\hline Basal metabolic rate & 160 & & $995-1775$ & 1315.2 & 160.14 \\
\hline Waist-to-hip ratio & 160 & & $0.69-1.11$ & 0.9 & 0.07 \\
\hline \multicolumn{6}{|l|}{ Mini Nutritional Assessment } \\
\hline Normal & 171 & 93.4 & & & \\
\hline Risk of malnutrition & 12 & 6.6 & & & \\
\hline Cognitive function & & & $11-30$ & 23.6 & 3.84 \\
\hline Complete & 100 & 54.6 & & & \\
\hline Mild cognitive dysfunction & 71 & 38.8 & & & \\
\hline Severe cognitive dysfunction & 12 & 6.6 & & & \\
\hline \multicolumn{6}{|l|}{ Sensory function } \\
\hline Sight (left eye) & & & $0.2-1.5$ & 0.8 & 0.2 \\
\hline Sight (right eye) & & & $0.1-2.0$ & 0.8 & 0.3 \\
\hline Cataract & 34 & 18.6 & & & \\
\hline Glaucoma & 6 & 3.3 & & & \\
\hline \multicolumn{6}{|l|}{ Hearing } \\
\hline Normal & 172 & 94 & & & \\
\hline One ear cannot hear clearly & 3 & 1.6 & & & \\
\hline Neither ears can hear clearly & 1 & 0.5 & & & \\
\hline
\end{tabular}




\begin{tabular}{|c|c|c|c|c|c|}
\hline Hearing loss in one ear & 4 & 2.2 & & & \\
\hline Hearing loss in both ears & 3 & 1.6 & & & \\
\hline \multicolumn{6}{|l|}{ Dental status } \\
\hline Missing teeth & 180 & 98.4 & & & \\
\hline False teeth & 15 & 8.2 & & & \\
\hline \multicolumn{6}{|l|}{ Assistive equipment } \\
\hline Wheelchair & 7 & 3.8 & & & \\
\hline Walker & 8 & 4.4 & & & \\
\hline \multicolumn{6}{|l|}{ Biochemical indices } \\
\hline Liver function (U/L) & & & $5-178$ & 23 & 17.6 \\
\hline Kidney function (mg/dL) & & & $0.6-4.5$ & 1 & 0.34 \\
\hline Blood glucose (mg/dL) & & & $70-214$ & 100.17 & 21.58 \\
\hline Total cholesterol (mg/dL) & & & $84-231$ & 135.55 & 27.51 \\
\hline High-density lipoprotein & & & $24-88$ & 45.55 & 12.30 \\
\hline Low-density lipoprotein & & & 26-191 & 71.33 & 24.22 \\
\hline Triglycerides & & & $34-304$ & 106.23 & 47.07 \\
\hline
\end{tabular}

Table 2. Differences in attributes, physiological state, cognitive function, and sensory function among patients with varying levels of frailty. 


\section{Basic attributes}

Sex

Male

Female

Age group

(1) 55-59 years

(2) 60-64 years

(3) 65-69 years

(4) 70-74 years

(5) 75 years or above

Educational attainment

(1) Primary school or under

(2) Junior high school

(3) Senior high school

(4) Junior college or higher

Hospitalization duration

(1) 1-5 year(s)

(2)6-10 years

(3) $11-15$ years

(4)15 years or longer

Physiological status

History of chronic disease

(1) Yes

(2) No

Hypertension
(1) Yes

(2) No

Diabetes

(1) Yes

(2) No

Hyperlipidaemia
(1) Yes

(2) No

Cardiovascular disease
(1) Yes
(2) No

Stage of frailty

Normal: $n(\%) \quad$ Pre-frailty: $n(\%) \quad$ Frailty: $n(\%)$

24.498

9(8.2)

11(15.1)

$8 \quad 4.047$

6(8.8)

$6(8.8)$

3(8.8)

3(15)

2(20)

$618.560^{* *}$

14(19.2)

4(6.3)

$0(0)$

2(14.3)

$620.036^{* *}$

$0(0)$

2(11.8)

$5(7.5)$

13(13.7)

\begin{tabular}{lll}
$4(100)$ & $0(0)$ & $0(0)$ \\
\hline $2(11.8)$ & $13(76.5)$ & $2(11.8)$ \\
\hline $22(32.8)$ & $40(59.7)$ & $5(7.5)$ \\
\hline $15(16.8)$ & $66(69.5)$ & $13(13.7)$
\end{tabular}

$2 \quad 1.427$

42(95.5) 117(98.3) 19(95)

2(4.5)

2(1.7)

1(5)

$2 \quad 1.262$

$5(25)$

30(68.2) 75(63) 15(75)

20.164

22(50) 55(46.2) 11(55)

22(50) 64(53.8) 9(45)

$2 \quad 2.267$

11(25) 18(15.1) 3(15)

33(75) 101(84.9) 17(85)

$2 \quad 0.292$ 


$\begin{array}{llll}\text { (1) Yes } & 11(25) & 40(33.6) & 9(45) \\ \text { (2) No } & 33(75) & 79(66.4) & 11(55)\end{array}$

Hepatitis or cirrhosis

\begin{tabular}{lllll} 
& & & 2 & 2.601 \\
\hline $11(25)$ & $40(33.6)$ & $9(45)$ & & \\
$33(75)$ & $79(66.4)$ & $11(55)$ & & \\
& & & 2 & 2.402 \\
\hline $12(27.3)$ & $26(21.8)$ & $2(10)$ & & \\
\hline $32(72.7)$ & $93(78.2)$ & $18(90)$ & & \\
\hline $1(2.3)$ & $9(7.6)$ & $2(10)$ & & \\
\hline $43(97.7)$ & $110(92.4)$ & $18(90)$ & & \\
\hline $2(4.5)$ & $9(7.6)$ & $3(15)$ & & \\
\hline $42(95.5)$ & $110(92.4)$ & $17(85)$ & & \\
\hline & & & 2.131 \\
\hline $0(0)$ & $2(1.7)$ & $4(20)$ & & \\
\hline $44(100)$ & $117(98.3)$ & $16(80)$ & & \\
\hline
\end{tabular}

$\begin{array}{llll}\text { (1) Yes } & 12(27.3) & 26(21.8) & 2(10) \\ \text { (2) No } & 32(72.7) & 93(78.2) & 18(90)\end{array}$

Cancer

(1) Yes

(2) No

Others
(1) Yes
(2) No

History of falls in the past year
(1) Yes
(2) No

$44(100)$

Type of medicine

Traditional antipsychotics
(1) Yes

(2) No

Second-generation antipsychotics

(1) Yes

Antidepressant
(1) Yes
(2) No

Mood stabilizer

(1) Yes
(2) No

Anxiolytics/tranquilizers and sleeping pills

\begin{tabular}{lll}
$12(27.3)$ & $37(31.1)$ & $7(35)$ \\
\hline $32(72.7)$ & $82(68.9)$ & $13(65)$
\end{tabular}

\section{$2 \quad 0.425$}

$2 \quad 3.367$

\begin{tabular}{lll}
\hline $40(90.9)$ & $105(88.2)$ & $15(75)$ \\
\hline $4(9.1)$ & $14(11.8)$ & $5(25)$ \\
\hline
\end{tabular}



(2) Risk of malnutrition

Cognitive function

(1) $>24$ points, complete function
(2) 18-23 points; mild impairment
(3) 0-17 points; severe impairment

Sensory function

Cataract

(1) Yes

(2) No

Glaucoma

(1) Yes

(2) No

Others

(1) Yes

(2) No

Dental status

Missing teeth

(1) Yes

(2) No

False teeth
(1) Yes
(2) No

Hearing

(1) Normal
(2) One ear cannot hear clearly

(3) Neither ears can hear clearly

(4) Hearing loss in one ear

(5) Hearing loss in both ears

Use of assistive equipment
(1) None
(2)Wheelchair
(3)Walker

(4)Obesity $>27$
Mini Nutritional Assessment

(4)Obesity $>27$
Mini Nutritional Assessment

(4)Obesity $>27$
Mini Nutritional Assessment
(1) Normal

12(27.3)

38(31.9)

$8(40)$

(20)

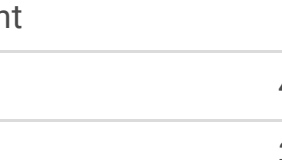

$\begin{array}{lll}41(93.2) & 113(95) & 17(85) \\ 3(6.8) & 6(5) & 3(15)\end{array}$

3(6.8)

$\begin{array}{lll}41(93.2) & 113(95) & 17(85) \\ 3(6.8) & 6(5) & 3(15)\end{array}$

$\begin{array}{lll}41(93.2) & 113(95) & 17(85) \\ 3(6.8) & 6(5) & 3(15)\end{array}$

\begin{tabular}{lll}
$26(59.1)$ & $70(58.8)$ & $4(20)$ \\
\hline $18(40.9)$ & $41(34.5)$ & $12(60)$ \\
$0(0)$ & $8(6.7)$ & $4(20)$
\end{tabular}

$\begin{array}{lll}41(93.2) & 113(95) & 17(85) \\ 3(6.8) & 6(5) & 3(15)\end{array}$

$2 \quad 2.777$

$4 \quad 16.281^{\star *}$

(2)

Cataract
(1) Yes
(2) No

\begin{tabular}{lll}
\hline $7(15.9)$ & $23(19.3)$ & $4(20)$ \\
\hline $37(84.1)$ & $96(80.7)$ & $16(80)$
\end{tabular}

\section{$2 \quad 0.278$}

$0(0)$

$5(4.2)$

1(5)

44(100) 114(95.8) 19(95)

$1(2.3) \quad 3(2.5) \quad 0(0)$

43(97.7) 116(97.5) 20(100)

21.998

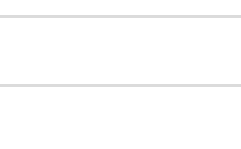

20.511

$2 \quad 0.444$

$\begin{array}{lll}43(97.7) & 117(98.3) & 20(100) \\ 1(2.3) & 2(1.7) & 0(0)\end{array}$

$2 \quad 4.579$

\begin{tabular}{lll}
$7(15.9)$ & $7(5.9)$ & $1(5)$ \\
\hline $37(84.1)$ & $112(94.1)$ & $19(95)$
\end{tabular}

\begin{tabular}{lll}
$42(95.5)$ & $111(93.3)$ & $19(95)$ \\
$0(0)$ & $3(2.5)$ & $0(0)$ \\
$0(0)$ & $1(0.8)$ & $0(0)$ \\
$2(4.5)$ & $2(1.7)$ & $0(0)$ \\
$0(0)$ & $2(1.7)$ & $1(5)$ \\
\hline
\end{tabular}

$\begin{array}{lll}44(100) & 118(99.2) & 6(30) \\ 0(0 & 1(0.8) & 6(30) \\ 0(0) & 0(0) & 8(40)\end{array}$

\footnotetext{
${ }^{\star} p<.05,{ }^{\star *} p<.01,{ }^{\star \star *} p<.001$.
}

$8 \quad 5.967$


Table 3. Differences in physiological state, cognitive function, sensory function, and biochemical indices of patients with varying levels of frailty.

\begin{tabular}{|c|c|c|c|c|c|c|}
\hline \multirow[t]{3}{*}{ Item } & \multicolumn{3}{|l|}{ Frailty } & \multirow[t]{3}{*}{$F$} & \multirow[t]{3}{*}{$p$} & \multirow{3}{*}{$\begin{array}{l}\text { Post hoc } \\
\text { comparison }\end{array}$} \\
\hline & Normal & Prefrailty & $\square$ Frailty & & & \\
\hline & $\mathrm{N}(M \pm S D)$ & $\mathrm{N}(M \pm S D)$ & $\mathrm{N}(M \pm S D)$ & & & \\
\hline Age & $44(62.34 \pm 4.68)$ & $119(63.64 \pm 6.28)$ & $20(65.10 \pm 6.70)$ & 1.571 & .211 & \\
\hline $\begin{array}{l}\text { Hospitalization } \\
\text { (days) }\end{array}$ & $44(5110.80 \pm 1680.02)$ & $119(5509.16 \pm 1315.71)$ & $20(5775.45 \pm 1085.05)$ & 1.962 & .144 & \\
\hline BMI index & $44(24.66 \pm 3.83)$ & $119(25.12 \pm 3.70)$ & $20(26.65 \pm 5.87)$ & 1.729 & .180 & \\
\hline \multicolumn{7}{|l|}{$\begin{array}{l}\text { Physiological } \\
\text { state }\end{array}$} \\
\hline $\begin{array}{l}\text { Weight of } \\
\text { body fat }\end{array}$ & $38(23.72 \pm 9.35)$ & $105(21.61 \pm 7.85)$ & $20(21.25 \pm 9.01)$ & 0.995 & .372 & \\
\hline $\begin{array}{l}\text { Skeletal } \\
\text { muscle } \\
\text { percentage }\end{array}$ & $38(22.59 \pm 3.05)$ & $105(23.79 \pm 4.83)$ & $20(26.48 \pm 3.63)$ & $5.256^{\star \star}$ & .006 & $\square>\square>\square$ \\
\hline $\begin{array}{l}\text { Basal } \\
\text { metabolic rate }\end{array}$ & $38(1275.29 \pm 110.02)$ & $103(1311.87 \pm 173.08)$ & $19(1412.84 \pm 135.65)$ & $4.971^{\star \star}$ & .008 & $\square>\square>\square$ \\
\hline $\begin{array}{l}\text { Waist-to-hip } \\
\text { ratio }\end{array}$ & $38(0.9 \pm 0.07)$ & $103(0.90 \pm 0.06)$ & $19(0.92 \pm 0.08)$ & 1.064 & .347 & \\
\hline $\begin{array}{l}\text { Cognitive } \\
\text { function }\end{array}$ & $44(25.05 \pm 3.25)$ & $119(23.57 \pm 3.96)$ & $20(20.90 \pm 2.81)$ & $8.726 * \star \star$ & $<.001$ & $\square>\square>\square$ \\
\hline \multicolumn{7}{|l|}{$\begin{array}{l}\text { Sensory } \\
\text { function }\end{array}$} \\
\hline $\begin{array}{l}\text { Sight (left } \\
\text { eye) }\end{array}$ & $44(0.85 \pm 0.19)$ & $119(0.83 \pm 0.24)$ & $20(0.73 \pm 0.25)$ & 2.087 & .127 & \\
\hline $\begin{array}{l}\text { Sight (right } \\
\text { eye) }\end{array}$ & $44(0.89 \pm 0.28)$ & $119(0.84 \pm 0.24)$ & $20(0.77 \pm 0.28)$ & 1.560 & .323 & \\
\hline \multicolumn{7}{|c|}{ Biochemical indices } \\
\hline $\begin{array}{l}\text { Liver function } \\
\text { (U/L) }\end{array}$ & $44(22.9 \pm 17.17)$ & $119(23.57 \pm 18.74)$ & $20(19.8 \pm 10.25)$ & 0.391 & .667 & \\
\hline $\begin{array}{l}\text { Kidney } \\
\text { function } \\
\text { (mg/dL) }\end{array}$ & $44(0.97 \pm 0.22)$ & $119(1.02 \pm 0.38)$ & $20(0.95 \pm 0.21)$ & 0.583 & .585 & \\
\hline $\begin{array}{l}\text { Blood glucose } \\
(\mathrm{mg} / \mathrm{dL})\end{array}$ & $44(100.7 \pm 20.48)$ & $119(101.11 \pm 23.14)$ & $20(93.4 \pm 11.47)$ & 1.112 & .331 & \\
\hline $\begin{array}{l}\text { Total } \\
\text { cholesterol } \\
(\mathrm{mg} / \mathrm{dL})\end{array}$ & $44(135.39 \pm 27.28)$ & $119(136.14 \pm 27.11)$ & $20(132.35 \pm 31.39)$ & 0.162 & .850 & \\
\hline $\begin{array}{l}\text { High-density } \\
\text { lipoprotein }\end{array}$ & $44(45.98 \pm 12.65)$ & $119(45.5 \pm 12.3)$ & $20(44.9 \pm 12.12)$ & 0.055 & .947 & \\
\hline $\begin{array}{l}\text { Low-density } \\
\text { lipoprotein }\end{array}$ & $44(70.39 \pm 22.45)$ & $119(71.96 \pm 25.05)$ & $20(60.65 \pm 24.02)$ & 0.120 & .887 & \\
\hline Triglycerides & $44(116.32 \pm 53.89)$ & $119(104.98 \pm 46.10)$ & $20(91.45 \pm 31.18)$ & 2.062 & .130 & \\
\hline
\end{tabular}

Table 4. Main predictors (attributes, physiological state, cognitive function, and sensory function) of frailty among the participants. 


\begin{tabular}{llllll} 
Independent variable & $\boldsymbol{\beta}$ value & Standard deviation & Wald & Significance & 95\% confidence interval \\
\hline Educational attainment & -0.098 & 0.182 & .290 & .590 & $-0.454 \sim 0.258$ \\
\hline Hospitalization duration & 0.000 & 0.000 & 3.464 & .063 & $0.000 \sim 0.001$ \\
\hline Skeletal muscle percentage & 0.850 & 0.781 & 1.185 & .276 & $-0.680 \sim 2.381$ \\
\hline Basal metabolic rate & -0.020 & 0.021 & .909 & .340 & $-0.063 \sim 0.022$ \\
\hline History of falls in the past year & 0.435 & 1.272 & .117 & .732 & $-2.058 \sim 2.928$ \\
\hline Anxiolytics/ & 0.204 & 0.364 & .313 & .576 & $-0.510 \sim 0.918$ \\
tranquilizers and sleeping pills & & & & & \\
\hline Cognitive function & -0.108 & 0.051 & 4.482 & $<.05^{\star}$ & $-0.207 \sim-0.008$ \\
\hline Use of assistive equipment & 4.247 & 0.974 & 19.005 & $<.001^{\star \star \star}$ & $2.337 \sim 6.156$
\end{tabular}

Note: Results reported for each factor were calculated with respect to the reference category of patients without frailty.

$\star p<.05,{ }^{* *} p<.01, * \star * \quad p<.001$. 